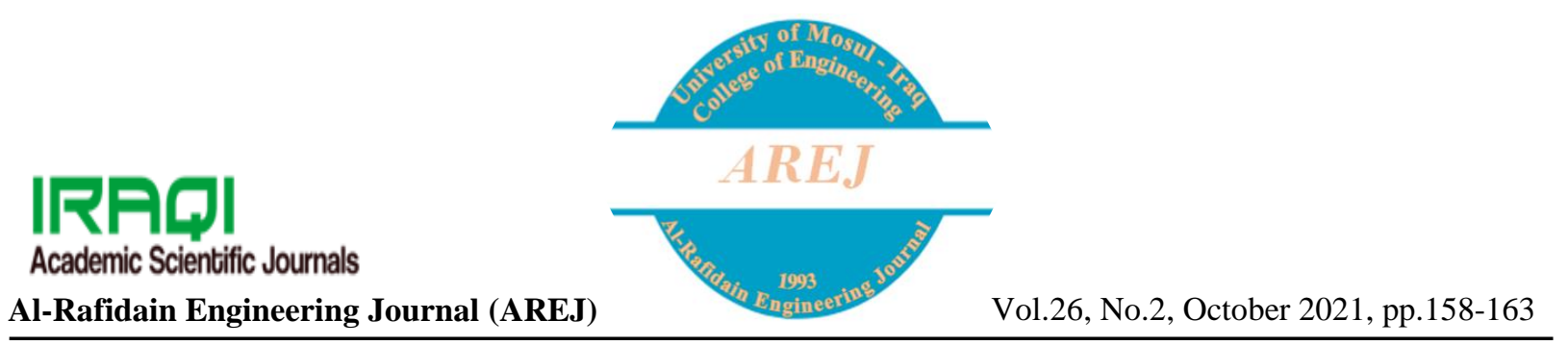

\title{
The Impact of Length of Frame on The Performance of Video Application in WiMAX System
}

\author{
Mohammed Younis Thanoun \\ myounisth@uomosul.edu.iq \\ Electrical Engineering Department, Collage of Engineering, University of Mosul
}

Received: 29/6/2021

Accepted: 18/7/2021

\begin{abstract}
The IEEE 802.16e standard includes several features that aid data capacity. When dealing with real-time applications such as video conference services, however, it quickly depletes its resources. The quality of the video, on the other hand, is a crucial factor for the user. There is a tradeoff between the video quality and the resources available. In this paper the influence of frame length on video applications was investigated by examining the effect of four frame lengths $(5,10,15$, and $20 \mathrm{mSec})$ on the Packet Delay Variation, End-to-end packet delay, traffic sent and received with modulation type 64QAM and high quality of video conference application are used. The optimal frame length was found to be 10 milliseconds, with the Packet Delay Variation being the smallest, the Packet End-to-End Delay being the shortest, and the number of received packets being equal to the number of sent packets.
\end{abstract}

Keywords:

IEEE 802.16e, video conference services, frame lengths, End-to-End Delay, 64QAM.

This is an open access article under the CC BY 4.0 license (http://creativecommons.org/licenses/by/4.0/). https://rengj.mosuljournals.com

\section{INTRODUCTION}

IEEE 802.16e is a standard that organizes the cell of a mobile WiMAX system and provides users with a variety of features to achieve the best possible service to users $[1,3,7]$. However, there is one very crucial factor that could cause the system to fail. When a video conferencing application is shared among multiple users, the size of the application data rate may surpass the system's capabilities. To put it another way, realtime applications are rapidly depleting the system.

In general, the conventional approach to providing video conferencing services is based on static video quality, which can result in one of two outcomes: the first saves cell capacity at the expense of video quality, while the second rapidly depletes cell capabilities. In the WiMAX system, the frame length has a considerable impact on video applications[3-5]. While guaranteeing that all sent packets arrive, the frame length must be adjusted to ensure that the packet delay Variation time is less than 30 milliseconds and the End-toEnd delay is as low as possible.

\section{Literature Review}

Academics are particularly interested in two aspects of this topic. Firstly, the system success criteria for specific users is the end-to-end delay and jitter of a video conference. The second trend is the examination of the WiMAX system to illustrate the distinctions between modulation and coding rate methods in real-time applications. For instance, but not exclusively:

K. Kaur and V. Grewal [8] proposed QoS analyzes scenarios in QPSK, 16QAM, or 64QAM modulation schemes with a $3 / 4$ coding rate for four fixed and mobile stations using QPSK, 16QAM and 64QAM modulatory schemes with a $3 / 4$ coding rate for 4 fixed and mobile stations using 64QAM, 16QAM, and QPSK modulation schematic schemes (48 stations). They worked with each modulation scheme independently, assuming that an end-to-end delay of fewer than 400 milliseconds was acceptable. They found that the QPSK modulation technique outperforms the 64QAM modulation approach in terms of traffic received, throughput, and packet end-to-end delay.

The influence of modulation techniques on video conference and voice applications was investigated by Mohammed and I. E. Abdalla in [9]. They offered three scenarios for WiMAX 
nodes, each of which represented a different modulation scheme with a single coding rate (QPSK1/2, 16QAM1/2, and 64QAM1/2).

[10] has chosen the Voice over IP application as a real-time application for analyzing the influence of QoS in a WiMAX system. This study proposed a system with seven BSs, each of which was followed by five stations. They concluded that VoIP apps would do better in the UGS service class.

\section{METHODOLOGY}

When employing the 64QAM modulation type and when the signal is strong, the effect of frame length on high-quality video applications in WiMAX systems was investigated in this work.

Fig. 1 illustrates the cell of WiMAX in the style of point to multipoint (P2MP). In this model, the uplink and the downlink directions are under base station (BS) controlled. The model includes BS connected to the server of the video conference to serve fixed users wirelessly. The BS of the cell defines the size of the signal-to-noise ratio of the wireless user in order to decide how modulation and code rate scheme every user is given. The BS then delivers a video conference service in collaboration with the server.

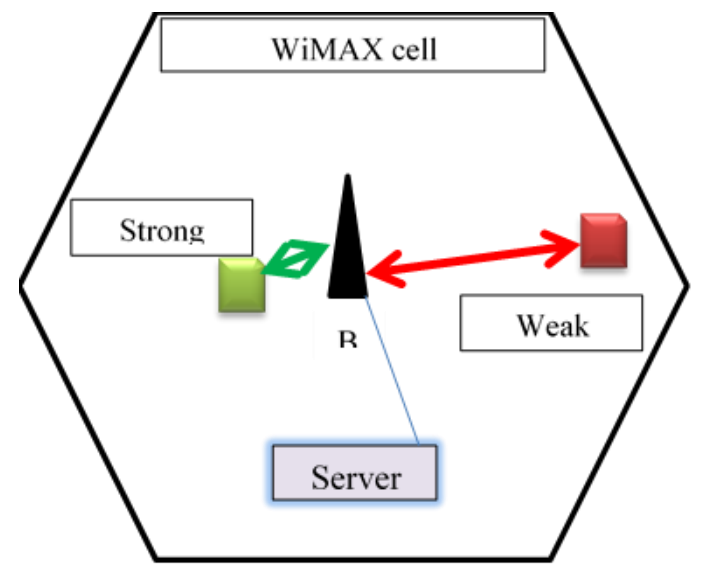

Fig. 1 The IEEE 802.16e standard's cell

\section{WiMAX Systems}

In order to support mobile WiMAX systems, the PHY of 802.16e is built on the OFDMA method [7]. This standard has the potential to replace older standards like 802.16a and 802.16d [2]. Furthermore, new characteristics have emerged as strong factors for this technology's support. It offers scalable OFDMA to provide flexibility in the number of subcarriers, with support ranging from 128 to 2048 subcarriers. Aside from that, the operating frequency range is lowered from $66 \mathrm{GHz}$ to $11 \mathrm{GHz}$ as a maximum value to accommodate the non-line of sight (NLOS) environment [13]. Coding rate, on the other hand, is the ratio of information bits to the total number of information bits plus extra bits. Instead of the reed Solomon and turbo codes used in older standards, the 802.16 e standard could handle a 5/6 code rate alongside $1 / 2,2 / 3$, and $3 / 4$ coding rates using convolutional code. Furthermore, adaptive modulation is a key component of the 802.16e standard. It supports modulation schemes like QPSK, 16QAM, and 64QAM. Furthermore, advanced techniques and optional features like the 4 by 4 MIMIO system and other antenna approaches [14] can support the capacity of this system.

\subsection{16e and Service Quality}

Every connection from user to BS or BS to user is categorized by service class [2] to provide QoS for various applications. The specification IEEE 802.16e enables the following scheduling of service class which coincide with different traffic types: nrtPS (Non-Real-Time polling service), rtPS (Real-time polling service), best effort (BE), UGS (unsolicited data grants), and ertPS (extended real-time polling service). The impact of frame length on video applications are the focus of this research.

The UGS class routinely produces fixed-size data and independently of the transmission request, the transmission chances criteria for users. In contrast to UGS, the rtPS class produces variablesize data and lets users to select grant size according on their requirements. The BE service class in BE has a characteristic style.

It is permitted for any user to make a reasonable request. Users' unicast requests to $\mathrm{BS}$, as well as unsolicited data grants, are collected by this service class [15].

\section{Service for video conferencing}

A video conferencing application is a live link between subscribers in different locations for communication [6]. The video conferencing program is widely utilized in a variety of disciplines, including the business world for meetings between managers and their employees, education for remote learning, and even the social and cultural realms.

A server that supports this application, as well as a wired or wireless network that connects users who want to access video conferencing, are required to implement videoconferencing. The fundamental issue with videoconferencing systems is that they deplete network resources because they require a very high data rate in addition to varying delay times [16]. 


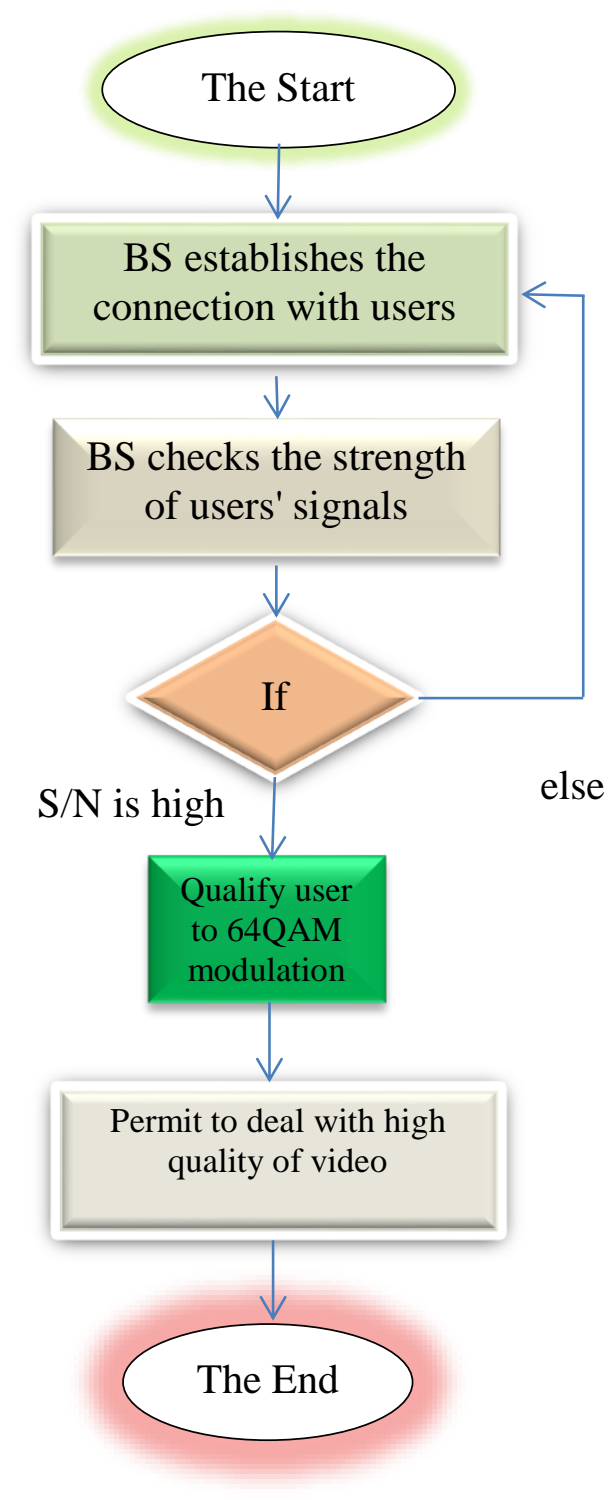

Fig. 2 The Work methodology

The upper limits of the overall delay time for video conferencing and the time lag have been calculated through research. As a result, it is extremely sensitive to E2E delay when there is no consensus on the best E2E number for this application [5]. Some sources say that an E2E delay of less than $400 \mathrm{msec}$ is acceptable [8], while others say that it should be less than $150 \mathrm{msec}$ [11] or less than $100 \mathrm{msec}$ [17]. Jitter, or the variation in delay between successive packets, has an impact on video conferencing; if the amount of jitter is increased, This real-time program will decrease performance; it should not go above 30 milliseconds[11]. Besides ETE delay and jitter, another video conferencing performance metric is packet loss. It is preferable not to exceed $1 \%$ [10$11]$.

It's worth noting that in order to provide a good video conference service for users, this article has developed a policy of four conditions. The first criteria are that the $802.16 \mathrm{e}$ cell has sufficient resources; the E2E delay should be less than $100 \mathrm{msec}$, jitter should not exceed $30 \mathrm{msec}$, and packet loss should not exceed $1 \%$. These restrictions represent the last line of defence before a system bottleneck occurs.

\section{The model Assumption}

The model in Figure (1) was implemented using OPNET Modeler 14.5 Table (1) explains the factors of the video application while table (2) handles the assumptions of the WiMAX system.

Table 1: video quality and resolution

\begin{tabular}{|c|c|}
\hline factor & description \\
\hline $\begin{array}{c}\text { Frame } \\
\text { interarrival }\end{array}$ & 15 frame/sec \\
\hline size & $\begin{array}{c}128^{*} 240 \\
\text { pixels }\end{array}$ \\
\hline
\end{tabular}

Table 2: model assumptions

\begin{tabular}{|c|c|}
\hline Assumption & Description \\
\hline Standard & WiMAX \\
\hline Duplexing & TDD \\
\hline $\begin{array}{c}\text { No. of } \\
\text { subcarriers }\end{array}$ & 2048 \\
\hline Time of symbol & $102.86 \mu \mathrm{sec}$ \\
\hline Time of frame & $5000 \mu \mathrm{sec}$ \\
\hline Frequency & $5 \mathrm{GHz}$ \\
\hline User & fixed \\
\hline type of service & rtPS \\
\hline Modulation & $64 \mathrm{QAM}$ \\
\hline Length of frame & $\begin{array}{c}5,10,15,20 \\
\text { msec }\end{array}$ \\
\hline
\end{tabular}

7. Results and discussions

\subsection{The results of E2E delay}

This section explains the results of end-to-end delay (E2E) for WiMax System as a term for the four scenarios $(5,10,15,20 \mathrm{msec})$. Figure (3) demonstrates the relationship between E2E delay and the frame length. It is noted that the E2E delay 
is increased with the increment of frame length in the first three scenarios. In the Fourth one (when frame length $=20 \mathrm{mSec}$ ) the E2E delay has a minimum value due to the effects of the packets lost as shown in Figure (4).

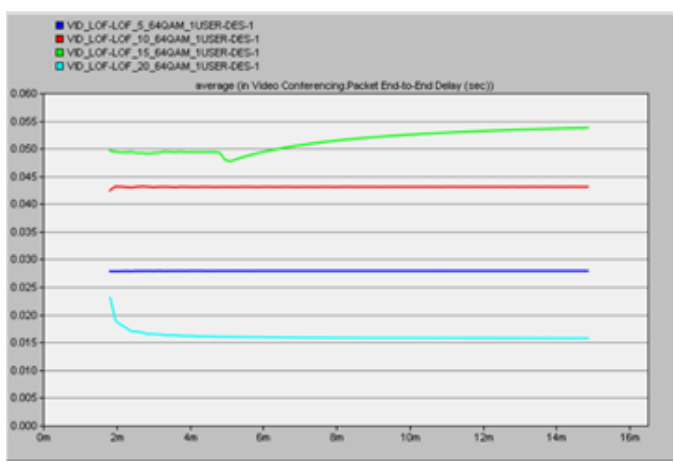

Fig. 3 End-to-End Delay

\subsection{The results of traffic received to sent}

The objective of this section of the results is to illustrate the traffic ratio provided to the received traffic. The proportion of the bytes successfully received in video conferences is calculated by traffic measurement received for given traffic (second). When this ratio yields a value of 100 percent, there have been no bytes lost. The link between the ratio of traffic received to traffic transmitted and the increment of frame length is depicted in Figure (4) for all frame length situations. As frame length grows, this ratio decreases. When the frame length is $5 \mathrm{msec}$ or 10 msec, the ratio is 100 percent; however, when the frame length is $15 \mathrm{msec}$ or $20 \mathrm{msec}$, the ratio lowers.

\subsection{The Packet Delay Variation}

The packet delay variation was shown in Figure (5). One of the video characteristics is jitter which means the variety in the time of the received packet, it represents the maximum value of jitter in four different frame lengths $(5,10,15$, and 20 $\mathrm{msec})$. It depicts the packet delay variation in all four scenarios; the variance rate is less than 30 msec, which is consistent with the video conference application requirements.

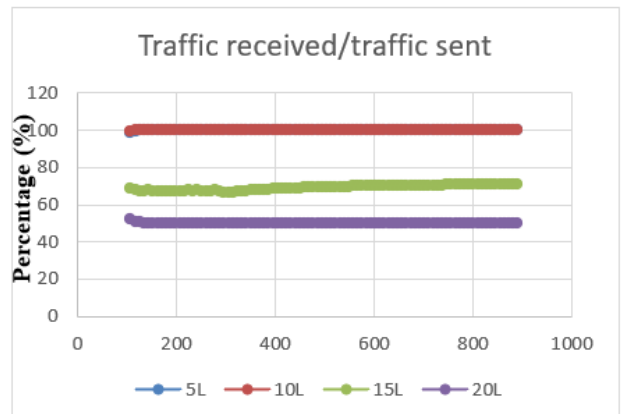

Fig. 4 traffic received to sent for all scenarios

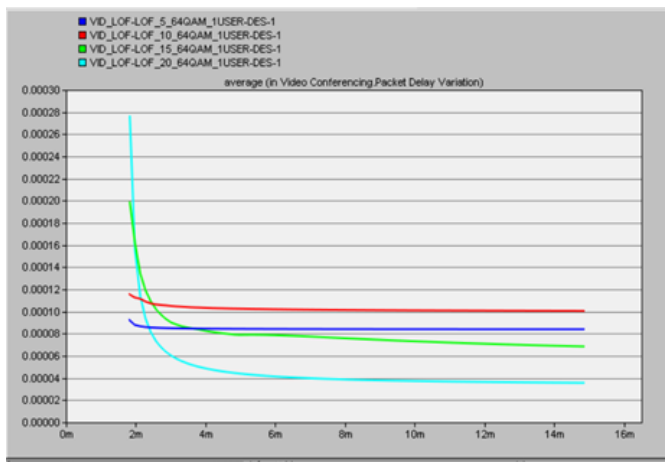

Fig. 5 packet delay variation for all scenarios

\section{Conclusion}

IEEE 802.16e is a standard that arranges a mobile WiMAX system cell with a number of characteristics to offer customers with the best service available. a new model developed to serve the users of $802.16 \mathrm{e}$ cell with video conference application and it concentrates on the relationship between High-quality video conference and frame lengths. The results show that the performance of the system under video conference application is divided into two approaches. The scenario performance $(15 \mathrm{msec}$ and $20 \mathrm{msec}$ ) explained the high delay as shown in the section of results. While the scenarios of $(5 \mathrm{msec}$ and $10 \mathrm{msec}$ ) explained appropriate performance from delay and jitter points of view. This is related to the small frame length size is more suitable for video conference applications (small size of the frame leads to less processing). 


\section{References}

[1] Ishgeem, Omar A., et al. "Analysis and Evaluation QoS of VoIP over WiMAX and UMTS Networks." 2021 IEEE 1st International Maghreb Meeting of the Conference on Sciences and Techniques of Automatic Control and Computer Engineering MISTA. IEEE, 2021.

[2] Wisdom, Daniel Dauda, et al. "An Improved Battery-Life Power Saving Scheme (IBPSS) in IEEE 802.16 e Networks." International Journal of Information Processing and Communication IJIPC 8.2 (2020).

[3] Al-Azzawi, Fatima Faydhe, et al. "Modulation and RS-CC rate specifications in WiMAX IEEE 802.16 Standard with MATLAB Simulink model." IOP Conference Series: Materials Science and Engineering. Vol. 881. No. 1. IOP Publishing, 2020.

[4] Kulkarni, J. (2020). Multi-band printed monopole antenna conforming bandwidth requirement of GSM/WLAN/WiMAX standards. Progress In Electromagnetics Research Letters, 91, 59-66.

[5] Simarata, J. H. T., and S. Suherman. "Downlink ratio impact on downstream traffic performances on WiMAX." IOP Conference Series: Materials Science and Engineering. Vol. 725. No. 1. IOP Publishing, 2020.

[6] Al-Akaidi, Marwan, and Yulianta Siregar. "Video streaming application with post-decoding concealment technique." Journal of Physics: Conference Series. Vol. 1783. No. 1. IOP Publishing, 2021.

[7] IEEE Standard 802.16-2005, "Part 16: Air Interface for Fixed and Mobile Broadband Wireless Access System", IEEE Standard for Local and metropolitan area networks, Revision of IEEE Std 802.16e, 28 Feb. 2006.

[8] K. Kaur and V. Grewal, "QoS Performance Analysis of Video Conferencing Over Wimax using different Modulation Schemes", International Journal of Computer Applications, vol. 146, issue 4, PP 33-37, 2016.

[9] A. A. Mohammed, and I. E. Abdalla, "Performance Evaluation of Voice and video conferencing For WIMAX Network under Various Modulation techniques" , Journal of Computer Engineering (IOSR-JCE), vol. 18, issue 4, PP 53-57, 2016.

[10] B. M. AL-Mahadeen and A. Al-Mseden, "Improving the QoS of VoIP over WiMAX Networks Using OPNET Modeler", IJCSNS International Journal of Computer Science and
Network Security, Vol.17, issue 8 PP 132-142, 2017.

[11] P. O. Umenne, and M. O. Odhiambo, "Performance Analysis of a WiMax/Wi-Fi System Whilst Streaming a Video Conference Application", International Journal of Electrical, Computer, Energetic, Electronic and Communication Engineering, vol. 7, issue 7, PP 846-850, 2013.

[12] N. R. Malankar, and R. Shah, "QoS Analysis over WiMAX Network with Varying Modulation Schemes and Efficiency Modes", International Journal of Computer Applications, Vol. 162, issue 8, PP 9-16, 2017.

[13] D. T. C. Wong, P.Y. Kong, Y..C. Liang, K. C. Chua, and J. W. Mark, "Wireless Broadband Networks", John Wiley \& Sons, 2009.

[14] K. C. Chen, and J. Roberto B. de Marca, "Mobile WiMAX", IEEE PRESS,2008.

[15] S. Ahson and M. Ilyas, "WiMAX Technologies, Performance Analysis, and QoS" , Taylor \& Francis Group, LLC, 2008 .

[16] A. E. Adewale, J. S. Soja, I.a T. Thuku, and H. James," An Investigative Study on Performance Metrics that Affects Video Conferencing over Wireless Network", International Journal of Innovative Research in Computer and Communication Engineering, Vol. 3, Issue 10, 2015.

[17] M. Baldi, and Y, Ofek, "End to End Delay of Video Conferencing over Packet Switched Networked",

[18] http:// www.opnet.com

[19] WHITE PAPER, "Preparing Your IP Network for High Definition Video Conferencing", Polycom, 2014. 


\section{تأثير طول الإطار على أداء تطبيقات الفيديو في نظام WiMAX \\ د. محمد يونس ذنون \\ myounisth@uomosul.edu.iq}

جامعة الموصل ـ كلية الهندسة ـ قسم الهندسة الكهربائية

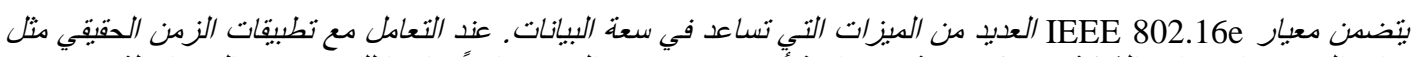

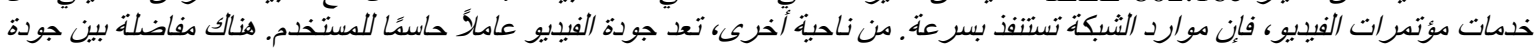

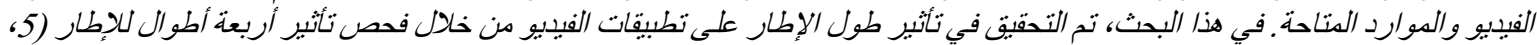

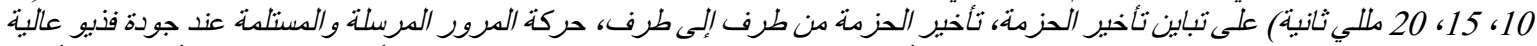

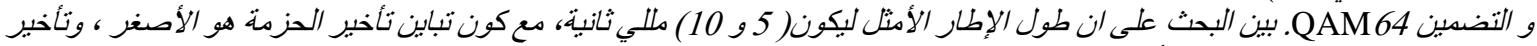

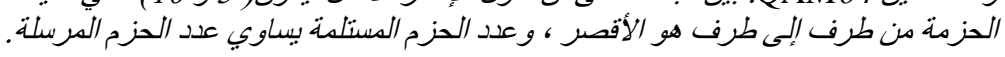

الكلمات الدالهه: معيار IEEE 802.16e، خدمات مؤتمرات الفيديو ، طول الاطار، وتأخبر الحزمة من طرف إلى طرف. 